\title{
FICCIÓN Y VERDAD
}

MARIO A. PRESAS

Universidad de La Plata y CONICET

"Lorsqu'ils pénetrent en nous, le tableau, la sonate, le poeme, mettent a notre portée notre propre naissance a la conscience. Et ils le font a un niveau de profondeur inaccesible par une autre voie".

George Steiner, Réelles Présences

En su obra sobre la crisis ${ }^{1}$, Husserl comienza por advertir que el sobredimensionamiento del pensamiento científico y de la actitud tecnológica, terminan por recubrir el mundo inmediato, subjetivo y relativo de la vida concreta de cada cual, la Lebenswelt, con un "vestido de ideas", exactas, universales, trasmisibles...pero no vividas. Varias décadas antes, Bergson denunciaba también una similar valoración errónea de la realidad y de la vida, que se debía, según el filósofo francés, al hecho de que el lenguaje y nuestras facultades cognoscitivas están configurados en vista de la acción, de la eficacia, y no de una pura contemplación. El hombre es en principio homo faber; ha de devenir homo sapiens en una conversión -similar también al papel que Husserl asigna en Krisis a la epoche, y que por lo pronto aquí podemos dejar a un lado- que lo llevará a la intuición metafísica. Tan sólo nos interesa destacar ahora el hecho de que ambos pensadores en cierto modo advierten que la percepción normal de la realidad y su enunciación en el lenguaje, no puede ser aceptada sin más como criterio absoluto y único de la verdad. En efecto, la vida social, la

\footnotetext{
${ }^{1}$ Edmund Husserl, Die Krisis der europäischen Wissenschaften und die transzendentale Phänomenologie. Hua VI, Zweiter Teil.

${ }^{2}$ Henri Bergson, Essai sur les données immédiates de la conscience. Paris, PUF, 1958, Avant-Propos (la obra fue escrita en 1888).
}

Éndoxa: Series Filosoficas, $n^{\circ} 2,1993$, UNED, Madrid:

Mario A. Presas: Ficción y verdad;

pp. $97-112$ 
necesidad de comunicación hace que de hecho y normalmente "olvidemos" lo realmente visto, oído, percibido, y lo traduzcamos en términos universalmente válidos, atendiendo más a la cantidad que a la cualidad de las experiencias. Mucho de esto, por lo demás, supieron y mostraron los pintores impresionistas, poco antes que Bergson lo expusiera en teoría: en general reemplazamos la visión inmediata por lo sabido de los objetos. $Y$, en el fondo, traducimos en términos espaciales -esto es, proyectamos sobre el medio homogéneo del espacio- las más profundas experiencias que sólo podrían comprenderse en la dimensión de la pura temporalidad, de la durée.

Este enfoque de Bergson encuentra su más acabado pendant literario en la obra de Proust A la recherche du temps perdu ${ }^{3}$. De allí partiremos para analizar la función cognoscitiva del lenguaje poético y del relato de ficción en relación con la temporalidad -siguiendo en especial el enfoque hermenéutico desarrollado por Paul Ricoeur-,e intentando así mostrar que la ciencia no es el único acceso a la realidad, ni el uso enunciativo del lenguaje el único modo de dar a conocer algo .

Proust expone de modo convincente el hecho de que lo que llamamos realidad no se agota en la sensación o en la percepción actuales, sino que siempre exige que esas sensaciones y percepciones actuales se vivifiquen en el recuerdo espontáneo, dentro del horizonte emotivo en que por primera vez tuvo lugar una experiencia. La misión del arte - la del escritor, en este casoconsiste en aprehender esa relación única entre las sensaciones y los recuerdos, "para encadenar para siempre en una frase los dos términos diferentes.(...) La verdad sólo empezará en el momento en que el escritor tome dos objetos diferentes, establezca su relación, análoga en el mundo del arte a la que es la relación única

\footnotetext{
${ }^{3}$ Marcel Proust, A la recherche du temps perdu. Paris, Bibliotheque de la Pleiade, NRF/Gallimard. Tres vol., 1958. Citaremos por la excelente versión española de Pedro Salinas y Consuelo Berges, edit. por Alianza, Madrid.
} 
de la ley causal en el mundo de la ciencia, y los encierre en los anillos necesarios de un bello estilo"4.

Ahora bien, esa visión conjunta de dos objetos diferentes, y la acuñación de esa semejanza en la palabra, equivale a lo que desde Aristóteles se llama metaforizar bien:"apercibir lo semejante"(Poet.1459 a 4-8). En tal sentido y a pesar de arraigadas opiniones en contrario que se apoyan en el positivismo lógico y en algunas direcciones de la lingüística y la crítica literaria, que niegan el carácter referencial y por ende la pretensión de verdad de todo discurso que no sea el informativo, y reducen la metáfora a un inocuo juego estético o una mera sintomatología emotiva, Paul Ricoeur sostiene que la metáfora traduce en una nueva pertinencia semántica un "ver-cómo" donde -como decía Proust"empieza la verdad" o al menos una dimensión de la misma que es descartada por la reducción positivista de la experiencia.

El examen de la metáfora nos permitirá además estudiar el relato de ficción, cuya función podemos definir anticipadamente como la ordenación sintética de múltiples sucesos en la unidad de una fábula en la que el hombre se cuenta (da cuenta de) la perplejidad de su propio experimentarse como ser temporal e histórico.

En la metáfora, es decir, al usar poéticamente el lenguaje, se produce una obstrucción de la referencia directa del discurso ordinario y el surgimiento de otra dimensión, hasta ahora inédita, de la relación con el mundo; en el relato de ficción,por su parte, el lenguaje, "despragmatizado", al contar destinos irreales, también posibilita que la obra proyecte ante sí un mundo virtual habitable. Por ello, no es sorprendente que la visión metafórica y la ficción narrativa configuren una suerte de horizonte contrastante sobre el cual se refleja la circunstancia real del lector, que, de ese modo, casi automáticamente, compara, corrige y critica sus propios supuestos.

\footnotetext{
${ }^{4}$ Marcel Proust, El tiempo recobrado, ed.cit, 1968, pp.238 s.
} 
El enfoque de la metáfora que hemos esbozado, no puede admitir teorias lingüisticas que privilegian la langue o el código a expensas de la parole o el uso -como es el caso de Saussure y el estructuralismo-. Pues en este caso la metáfora sólo puede concebirse como una denominación desviante, un simple desplazamiento o sustitución del sentido de las palabras. En cambio, teorías como la de Benveniste, para las cuales la palabra aislada tan sólo cobra su cabal sentido en la frase, tomada como unidad elemental portadora de la significación minima completa, dan cuenta de un modo más correcto del sentido que tiene el uso metafórico, pues pueden explicar cómo la primera suspensión de la referencia normal, es decir el desvío del sentido literal del discurso descriptivo, no agota la totalidad del movimiento metafórico, sino que es tan sólo "la condición negativa para que se despeje un modo más fundamental de referencia, que debe ser explicitado por la interpretación" ${ }^{15}$. Resumiendo, puede decir Ricoeur en otra obra, que los textos poéticos, ya sean líricos o narrativos, "también hablan del mundo, aunque no lo hacen de manera descriptiva. La referencia metafórica(...) consiste en el hecho de que el oscurecimiento de la referencia descriptiva -oscurecimiento que, en una primera aproximación, reenvía al lenguaje sobre sí mismo-se revela siendo , en una segunda aproximación, la condición negativa para que sea liberado un poder más radical de referencia a aspectos de nuestro ser-en-el-mundo que no pueden ser dichos de manera directa"6.

Ese trabajo de la metáfora es obra de la esquematización de la imaginación productiva, entendida como "esta competencia, esta capacidad de producir nuevas especies lógicas por asimilación predicativa, de producirlas a despecho de -y gracias a- la diferen-

\footnotetext{
${ }^{5}$ Paul Ricoeur, La metáfora viva, Buenos Aires, Megapolis, 1977, p. 342. Cfr. Mario A. Presas, "La verdad de la ficción", Revista Latinoamericana de Filosofía,Buenos Aires. XIV/2 (julio 1988).

${ }^{6}$ Paul Ricoeur, Temps et récit.Tomo I., Paris, Seuil, 1983, pp.120 s.
} 
cia inicial entre los términos que se resisten a la asimilación"7. No en vano recurre Ricoeur a esa terminologia, ya que el propio Kant, al describir la imaginación como facultad productiva de conocimiento, afirma que "es muy poderosa en la creación, por así decirlo, de otra naturaleza, sacada de la materia prima que la verdadera le da"'.

$\mathrm{Si}$ pudiéramos reproducir lo que ha pasado por la mente de aquel a quien por primera vez se le ocurrió (vio), pongamos por caso, la metáfora del hombre como lobo del hombre, - a pesar de que, como dice Borges, es quizás un error suponer que puedan inventarse metáforas - veríamos que se trata de un proceso por el cual no todo el sistema de tópicos que acompañan al tema principal hombre y al tema subsidiario lobo entran en la composición metafórica. Más bien sucede como cuando contemplamos el cielo estrellado a través de un trozo de vidrio ennegrecido, en el que se han dejado sin cubrir algunas líneas - como dice Max Black 10 -; se ven entonces únicamente los astros que pueden caer sobre esas líneas preparadas previamente, los que, además, aparecerán organizados por la estructura de esa pantalla."Podemos considerar la metáfora como una pantalla semejante- prosigue Max Black - y el sistema de 'tópicos acompañantes' de la palabra focal; como la red de líneas trazadas sobre ella; asimismo podemos decir que el

\footnotetext{
7 Paul Ricoeur, 'De l'interprétation", en Du texte a l'action. Essais d'herméneutique II. Paris, Esprit/Seuil, 1986. p.21. Cfr.Mario A. Presas, "La re-descripción de la realidad en el arte", Revista Latinoamericana de Filosofía,Buenos Aires. XVII/2(Primavera 1991).

${ }^{8}$ I. Kant, Kritik der Urteilskraft, \#49.

${ }^{9}$ J. L. Borges, "Nathaniel Hawthorne", en Nueva antología personal, Barcelona, Bruguera, 1980, p. 213: "No sé quién la inventó [a una metáfora]; es quizás un error suponer que puedan inventarse metáforas. Las verdaderas, las que formulan conexiones íntimas entre una imagen y otra, han existido siempre; las que aún podemos inventar son las falsas, las que no vale la pena inventar".

${ }^{10}$ Max Black, "La metáfora", en Modelos y metáforas, Madrid, Tecnos, 1966, p.51. Cfr. ahora también U. Eco, "De la interpretación de las metáforas", en Los límites de la interpretación, Barcelona, Ed. Lumen, 1992, pp.160 ss., donde hay interesantes referencias precisamente a los textos aquí citados de Ricoeur, Black y Hesse. Lamentablemente encuentro este texto de Eco cuando ya había escrito mi trabajo; aunque de todos modos hay coincidencia en la argumentación.
} 
asunto principal 'se ve a través' de la expresión metafórica, o, si así lo preferimos, que resulta 'proyectado sobre' el campo del asunto subsidiario".

Asi, pues, tanto la metáfora como el modelo bien merecen el título de "ficciones heurísticas" que Kant asignaba a las Ideas de la Razón ${ }^{11}$; su función consiste en proyectar un marco interpretativo previo que deseche una concepcion de la realidad asentada en el lenguaje corriente, considerada ahora incorrecta. En tal sentido son - como dice Mary Hesse- "instrumentos de re-descripción" por medio de los cuales constantemente adaptamos nuestro lenguaje a un mundo que se nos presenta en una continua expansión ${ }^{12}$.

Pero la comparación con algunos modelos científicos, expuesta precisamente por los mencionados epistemólogos, suscita además otra reflexión: en efecto, si bien "no cabe duda de que hay cierta semejanza entre el empleo de un modelo y la metáfora", se trata más exactamente, en el caso del modelo, de "una metáfora continuada y sistemática", de tal modo que, en rigor, el equivalente lingüístico del modelo sería una red metafórica - por así decirlo que se ordena, por ejemplo, en el trabajo sintético de un relato de ficción. En la metáfora, decíamos, la innovación semántica se produce en virtud de una atribución impertinente; en el relato, en cambio, por medio de la invención de un mito, una fábula, un "argumento" - lo que Ricoeur con felíz expresión denomina mise en intrigue ${ }^{13}$ - en virtud de la cual fines aparentemente casuales, detalles triviales, peripecias imprevistas, etc., son re-unidos, com-puestos, en la unidad temporal de una historia ficticia; consiste principalmente en la selección y el arreglo de los acontecimientos y de las acciones contadas, que hacen de la fábula "una acción total y completa"(Poet.1450 b 25)con un comienzo, un medio y un fin. Se trata en definitiva de una "síntesis de lo heterogéneo"

\footnotetext{
${ }^{11}$ I. Kant, Kritik der reinen Vernunft, A 671 /B 699 y A 771/B 799.

${ }^{12}$ Mary Hesse, "The explanatory Function of Metaphor", cit. por Ricoeur, La metáfora viva, ed. cit., p.357.

${ }^{13} \mathrm{Cfr}$. Paul Ricoeur, Temps et récit, ed. cit., Tomo , cap.2: "La mise en intrigue. Une lecture de la Poétique d'Aristote", pp. 55 ss.
} 
que no difiere en mucho de aquella "relación" aludida por Proust.

La lectura o la visión en el teatro de esa síntesis arroja cierta claridad sobre la propia vida del lector/espectador pues hace transparecer más nítidamente el sentido que en las acciones cotidianas está confundido -fundido con- mil detalles que lo oscurecen. Esta inteligibiliodad nos libera (catharsis) de la angustia de no ser dueños de nuestra propia existencia, en tanto no somos capaces (ontológicamente) de "madurar" (es uno de los sentidos de Zeitigen, verbo que Heidegger relaciona íntimamente con el Dasein en Sein und Zeit) nuestra propia muerte; no dominamos ni el principio, ni el medio, ni el fin...

Denn dieses macht das Sterben fremd und schwer, dass es ist nicht unser Tod ist ${ }^{14}$.

Las intrigas que inventamos - sostiene Ricoeur- constituyen el medio privilegiado por el cual re-configuramos nuestra experiencia temporal confusa, informe, y en el limite muda. San Agustín decía -como es bien conocido- que sabía lo que era el tiempo, pero tan sólo para sí, pues si alguien se lo preguntaba ya no podía dar respuesta. Según Ricoeur, la capacidad narrativa del hombre da una respuesta poética a este enigma del tiempo que sume en la perplejidad a científicos y filósofos. $Y$ precisamente en "esa capacidad de la ficción de re-figurar la experiencia temporal" reside lo que llama "función referencial"-es decir, la verdad- "de la intriga"15.

Pero, como es obvio, el texto en que puede leerse la intriga no brinda una explicación unívoca y clara . Exige el esfuerzo metódico de la interpretación. Ante el texto, podemos decir, estamos desguarnecidos: ya no hay un interlocutor frente a mí, cuyas palabras pueda aclarar con gestos o definiciones ostensivas que

\footnotetext{
14 "Pues esto es lo que hace el morir extraño y difícil: que no es nuestra muerte", canta Rilke en Das Stunden-Buch, para concluir luego con la plegaria:"iOh Señor! da a cada uno su propia muerte. El morir que surje de aquella vida en la que él tuvo amor, sentido y necesidad".

${ }^{15}$ Temps et récit, T.I., ed. cit., p.13.
} 
apuntan al mundo circundante común. Han desaparecido o mejor se han ocultado los autores y los lectores; de un modo semejante, la metáfora destruía en primer lugar la referencia ordinaria.

Ricoeur se esfuerza por conciliar las dos vías- a su juicio unilaterales y totalitarias- que han tratado de dar respuesta a los problemas que plantea la interpretación de un texto: por un lado la pretendida inmediatez irracional de una comprensión empática (Einfühlung) a la que se revelaría la mente del autor; por otro, el reduccionismo de la explicación que pretende extender al texto el análisis estructural de los sistemas de signos que son más propios de la langue que del texto.

En el primer caso, Dilthey creyó poder completar la obra epistemológica de Kant, pues pensaba que el límite de la incognoscibilidad de la cosa en sí que se da en el orden de las ciencias de la naturaleza, no existe en el plano de las Geisteswissenschaften, puesto que aquí el objeto es el otro, el alter ego, al que puedo conocer tan bien como me conozco a mí mismo. De allí concluía que por la comprensión de las vivencias expresadas en un texto era posible revivir congenialmente la disposición psicológica del autor al crearlo. Pero, con este enfoque - sostiene Ricoeur - nos enredamos en una estrategia psicologista que poco o nada tiene que ver con "la cosa del texto". Hoy en día, después de Nietzsche, Marx y Freud, ya no somos tan ingenuos con respecto a las suposiciones del conocimiento de sí mismo y de los demás ${ }^{16}$.

Por otro lado, el estructuralismo creyó encontrar por fin una metodología científica- y no ad hoc- aplicable también a los textos; pero con ello reduce la explicación al sentido (Sinn), a costas de la connotación o referencia (Bedeutung), tal como si explicáramos el mecanismo de relojería de una metáfora pero sin acertar a elucidar qué nos está diciendo acerca de la realidad.

\footnotetext{
${ }^{16} \mathrm{Cfr}$. Ricoeur, Du texte a l'action, ed. cit., p.90. Recientemente ha proseguido estas dificultades de la autocomprensión en Soi-meme comme un autre, Paris, Seuil 1990. Cfr. Mario A. Presas, "El otro en el sí mismo", La Nación,Buenos Aires, 5.5.91.
} 
Ambos enfoques son unilaterales, pues un texto no se agota en la mostración de una totalidad irreferente de signos interrelacionados, ni necesariamente coincide su significación con la pretendida intención del autor. Aunque esto suene demasiado obvio, hay que empezar por recordar que un texto reclama un lector para concretarse como tal texto.

En efecto, el texto no esta allí como totalidad acabada; el texto sólo se manifiesta, por así decirlo, en y por medio de la lectura. En virtud de esta necesidad esencial, toda obra trasciende sus propias condiciones psico-sociológicas de producción y se abre a una serie ilimitada de lecturas, situadas ellas mismas en contextos socioculturales diferentes. "El texto debe poder descontextualizarse, tanto desde el punto de vista sociológico como desde el psicológico, de tal manera que se deje recontextualizar en una nueva situación: esto es precisamente lo que hace el acto de leer"17.

La descripción fenomenológica de un texto muestra que éste necesariamente presenta "lugares de indeterminación", "vacíos" como dice Ingarden ${ }^{18}$ - que exigen ser plenificados, concretizados por medio de la actividad perceptiva y la actividad imaginante del lector; pues leer implica percibir lo escrito (real), pero suscitando en ello la aparición de lo imaginario (irreal), en un proceso similar al del actor, que -como lo ha descrito Sartre- "presta" su realidad corporal y psíquica -se desrealiza-, para que en su cuerpo, convertido en analogon, aparezca el personaje ${ }^{19}$. En la lectura, el lector va produciendo un objeto imaginario "en el que logra manifestarse lo que el texto formulado calla" ${ }^{\prime 20}$.

Estas concretizaciones (Konkretisationen) o bien actualizaciones (Aktualisierungen), correlatos del acto de leer - según la terminología de Ingarden - , están en lo esencial reguladas por el texto, aunque de hecho son tan infinitas como lo sería la empresa de

\footnotetext{
${ }^{17}$ Du texte a l'action, ed. cit., p.111.

${ }^{18}$ Das literarische Kunstwerk, Tübingen, Niemeyer, 4a.ed.1972. Cfr. especialmente \#\#38 ss:"Die Unbestimmtheitsstellen der dargestellten Gegenständlichkeiten".

${ }^{19}$ J.-P. Sartre, Lo imaginario. Buenos Aires, Losada, 2a. ed., 1968, p.245.

${ }^{20}$ Wolfgang Iser, El acto de leer. Madrid, Taurus, 1987, p. 235.
} 
plenificar todas las determinaciones posibles mentadas (co-mentadas) en la percepción de una cosa real. La parte escrita, la que nos informa, pasa a ser en el texto ficcional la oportunidad de figurarnos o imaginarnos cosas, sucesos, personajes; pero "sin los elementos de indeterminación, sin los huecos del texto, no seríamos capaces de usar nuestra imaginación" - apunta Iser en otro ensayo ${ }^{21}$-, pues efectivamente rige aquí la recíproca exclusión de los actos de percibir y los de imaginar que Sartre (siguiendo a Husserl) expuso con mucha claridad en su temprana obra sobre Lo imaginario que acabamos de citar.

Con otras palabras: el acto de leer sigue las instrucciones marcadas por el texto literario; pero de todos modos no trasmite un conocimiento, una información susceptible de ser traducida sin residuos en enunciados descriptivos. Actúa simultáneamente aquí un halo emotivo, una Stimmung, como vehículo de comprensibilidad, pues en esta dimensión -como dice Nelson Goodman- "las emociones funcionan cognoscitivamente"22. De ahí que podriamos decir más bien -como lo hace Kant respecto de las "ideas estéticas"que la lectura de un texto, si bien no da un conocimiento, "da mucho que pensar". En efecto, se trata de un lenguaje multívoco que, en la exhibición de un caso particular, permite la aparición de un universal.Es un lenguaje simbólico- en el sentido que le dieron Kant y los románticos al símbolo, opuesto a la alegoría- que acoge "representaciones inexponibles de la razón", al que "no puede serle adecuado ningún concepto y que, por lo tanto, ningún lenguaje expresa del todo ni puede hacer comprensible"; pero son justamente esas "representaciones de la imaginación" las que "animan las facultades de conocimiento e introducen espíritu en el lenguaje de las simples letras"

\footnotetext{
21 "El proceso de la lectura: un enfoque fenomenológico", en J. A. Mayoral (comp.), Estética de la recepción. Madrid, Arco, 1987, p.227.

${ }_{22}^{22}$ Nelson Goodman, Languages of Art, Indianapolis, Bobbs-Merril, 1968, p. 248.

${ }^{23}$ I. Kant, Kritik der Urteilskraft, \# 49.
} 
Así, pues, si bien los textos de ficción "no reproducen los objetos existentes", sino que "más bien proyectan sus objetos" -como señala Iser $^{24}$-, ello no significa que ficción y realidad simplemente se opongan; sino más bien que la ficción es la estructura lingüistica capaz de organizar la realidad de manera tal que ésta sea comunicable. Por ello, podemos decir ahora que "en vez de ser su mero opuesto, la ficción nos comunica algo sobre la realidad".

Esta comunicación, como veíamos, se actualiza por la lectura, la cual, como la ejecución de una partitura musical -ique siempre es, como lo dice inclusive nuestro lenguaje, una interpretación!pone en acto las posibilidades semánticas del texto. Pero hay que observar aún que el acto de lectura es en realidad una apropiación: hace propio lo ajeno y distante del otro. Pone lo propio para volver a conectar el texto con el mundo y lo vuelve a llenar de vida como si fuera una instancia del discurso, dándole la carne de la Lebenswelt del lector. De todos modos, la lectura no sustituye al diálogo, a pesar de esa re-actualización del texto y de su re-insersión en el mundo; pero la lectura, así entendida, constituye un acto que es al texto lo que la parole es a la langue: acontecimiento e instancia de discurso. Así se equilibra y completa lo que las opuestas estrategias interpretativas del Erklären y del Verstehen dejaban en suspenso. Con el análisis estructural -concluye Ricoeur- "el texto tenía solamente un sentido, es decir, relaciones internas, una estructura; ahora (con la lectura como interpretación apropiadora) tiene además una significación (referencia), es decir, una efectuación en el discurso propio del sujeto que lee. Por su sentido, el texto tenía solamente una dimensión semiológica; ahora, por su significación, tiene además una dimensión semántica"25.

De todos modos, ahora queda en pie la tarea de "explicitar la suerte de ser-en-el-mundo desplegado delante del texto". Para ello es preciso entrar en el juego de los imaginarios: el mundo del texto

\footnotetext{
${ }^{24} \mathrm{El}$ acto de leer, ed. cit., p.92; ver también p. 50.

25 "Qu'est-ce qu'un texte?", en Du texte a l'action, ed. cit., p.153.
} 
es, en definitiva, una trascendencia en la inmanencia de las estructuras; dicha trascendencia, por más fantasiosa que sea la intrigue, no deja de ser una variación imaginaria del mundo en la que el lector entra - supuesto lo que Coleridge llamaba willing suspension of disbelief -tan sólo participando en el juego, haciendo jugar también él variaciones imaginarias de su ego - como dice Ricoeur tomando en préstamo estos términos tan caros a Husserl-.

Por eso Poulet puede decir, paradójicamente, que al leer, el lector parece ser "la conciencia de un mundo de pensamientos que se va pensando en él... y son los de otro"."Todo lo que pienso (como lector) es parte de mi mundo mental. Y sin embargo aquí me encuentro teniendo un pensamiento que manifiestamente pertenece a otro mundo mental que está siendo pensado en mí tal y como si yo no existiera. (...) Siempre que leo, pronuncio mentalmente un yo. $Y$, sin embargo, el yo que pronuncio no es yo mismo"26. Esta singular comprobación, explica Iser, válida siempre que no se la hipostasíe 'a la Hegel, ilumina la relación entre las ideas del otro, que la lectura convierte en mi tema, y el trasfondo de mi propia visión del mundo y de la vida sobre el cual son recibidas, aun cuando estas creencias sean dejadas a un lado, en la medida en que ello es posible, al efectuarse lo que Gadamer llama "una efectiva fusión de horizontes". De otro modo no comprenderíamos un texto, ni lograríamos captar, en general, el sentido de un suceso pasado narrado en una historia o una crónica.

En este punto -más allá de nuestro tema de la lectura- radica el punto central de la hermenéutica, pues aquí ha de tener lugar la applicatio del texto a nosotros mismos, en virtud de la naturaleza misma del hombre en cuanto "wirkungsgeschichtliches Bewusstsein"- acertada pero casi intraducible acuñación de Gadamer que Ricoeur vierte como "la conscience d'etre exposé a l'efficience de l'histoire" o, más literalmente, en otro lugar, "la conscience-de-l'his-

\footnotetext{
${ }^{26}$ Georges Poulet, "Phenomenology of Reading", cit. por Iser, El acto de leer, ed. cit., p.244.
} 
toire-des-effets.(...) C'est la conscience d'etre exposé a l'histoire et 'a son action, d'une maniere telle qu'on ne peut objectiver cette action sur nous, parce qu'elle fait partie du phénomene historique lui-meme ${ }^{127}$. Gabriel Marcel hubiera llamado a esta imposibilidad de objetivación, es decir, de tratar una cuestión como un problema cuyos datos pueden hacerme frente, ser puestos frente a mí, pues esos datos" son yo mismo", son los que me hacen ser yo mismo, lo metaproblemático, o simplemente, la dimensión del misterio ${ }^{28}$

Esta función hermenéutica es doble: por una parte, se trata de suprimir la distancia (la extraneidad); y, por otra, de hacer propio lo que se interpreta. Al ejercitarse espontáneamente en la lectura, esta doble tarea hermenéutica trae a la memoria ideas que Proust pone en boca de su personaje -y que tan sólo se comprenden en plenitud si se tiene en cuenta lo que deciamos acerca de Bergson, a saber, que "el deber y el trabajo de un escritor" es equiparable al "deber y al trabajo de un traductor", pues, en definitiva, la indagación del artista en su propia vida no tiene otra finalidad que la de recuperar lo propio, oscurecido, cegado, sepultado por las necesidades prácticas, los hábitos, todas las sedimentaciones de la costumbre que, como las arenas que va depositando un río de llanura en su desembocadura, terminan por impedir la libre circulación de las aguas. Aún en nuestra" época de prosa" -como decía Hegel al fin de sus Lecciones de Estética, luego de comprobar que el arte ya no podía ser para nosotros la suprema determinación del espíritu-, el arte conserva una función crítica insoslayable, que produce nada menos que "la liberación del espíritu del contenido y de las formas de la finitud"

${ }^{27}$ H. G. Gadamer, Wahrheit und Methode, Tübingen, Mohr(Siebeck), 4a.ed., 1975, p. 290. Ricoeur, Temps et récit, Tomo III, p. 314; y Du texte a l'action, p.98.

${ }_{28}^{28}$ Gabriel Marcel, "El misterio ontológico. Posición y aproximaciones concretas", en Mario A. Presas, Gabriel Marcel, Buenos Aires, Centro Ed. de América Latina, 1967, pp.49 ss.

${ }^{2}$ Hegel, Aesthetik, hrsg. v. Fr. Bassenge. Berlin, Aufbau, 1955, p.1105. Cfr. Mario A. Presas, "La 'muerte del arte' y la experiencia estética", Diálogos, Puerto Rico, 40 (1982), pp.61-70. 
Así, pues, desde distintas perspectivas, muchos filósofos y escritores coinciden en señalar esa acción corrosiva del arte, capaz de remontar hacia atrás la inevitable tentación estatizante y espacializante de la vida social y práctica que Proust resume maravillosamente en las páginas más "teóricas" de Le temps retrouvé:"Ese trabajo del artista, ese trabajo de intentar ver bajo la materia, bajo la experiencia, bajo las palabras, algo diferente, es exactamente el trabajo inverso del que, cada minuto, cuando vivimos apartados de nosotros mismos, el amor propio, la pasión, la inteligencia y también la costumbre, realizan en nosotros cuando amontonan encima de nuestras impresiones verdaderas, para ocultárnoslas enteramente, las nomenclaturas, los fines prácticos que llamamos falsamente la vida' ${ }^{130}$.

Ese proceso de anquilosamiento y petrificaciónm es el que ha de destruir el arte, marchando contra la corriente que tiende a la pesadez de la materia, y retornando hacia aquellas profundidades "donde yace, desconocido por nosotros, lo que realmente ha existido"31.

El lector recibe del autor la "ficción heurística" que es el texto, que reúne experiencias traducidas en "equivalentes de inteligencia", con lugares de indeterminación, con vacíos,... con la constante apelación a que quien lee ponga lo propio, se apropie de ese mundo proyectado ante la obra, "pues, en realidad, cada lector es, cuando lee, el propio lector de sí mismo. La obra del escritor no es más que una especie de instrumento óptico que ofrece al lector para permitirle discernir lo que, sin ese libro, no hubiera podido ver en sí mismo. El reconocimiento en sí mismo, por el lector, de lo que el libro dice, es la prueba de la verdad de éste ${ }^{\prime \prime 32}$.

En virtud del trabajo de la lectura y la apropiación, se manifiesta lo que Steiner llama una presencia real, de otro modo inaccesible, hasta el punto que bien puede decirse que la literatura y el arte

\footnotetext{
${ }^{30}$ El tiempo recobrado, ed. cit., p. 246.

${ }^{31}$ Proust, El tiempo recobrado, p. 247.

${ }^{32}$ Proust, El tiempo recobrado, p.264.
} 
"ponen a nuestra disposición nuestro propio nacimiento a la conciencia"33 $y$, en tal sentido, una dimensión "anterior" a toda conceptualización, donde la presencia ha de ser reconocida por el lector; pero no tratada como un objeto manipulable.

Gabriel Marcel resume escuetamente estas ideas en una fórmula que da que pensar:"La presencia sólo puede invocarse o evocarse, y la esencia de la invocación es mágica". ${ }^{34}$

No otra cosa confesaba el poeta, al contraponer la mecanización de un mundo des-encantado (entzauberte Welt, como dice Max Weber), explicado por la razón instrumental, al encantamiento de la existencia(verzaubertes Dasein):

Aber noch ist uns das Dasein verzaubert; an hundert

Stellen ist es noch Ursprung. Ein Spielen von reinen

Kräften, die keiner berührt, der nicht kniet und bewundert ${ }^{35}$.

A modo de indicación, quisiera añadir, por último, que tanto Proust como Rilke parecen sospechar que, al culminar el acceso a la realidad todavía "traducible" en el lenguaje poético, rozamos otro modo de comunicación que supera a toda palabra: la música. En efecto, en La prisionera, el narrador confiesa: " $Y$ así como algunos seres son los últimos testigos de una forma de vida que la naturaleza ha abandonado, me preguntaba si no sería la música el ejemplo único de lo que hubiera podido ser la comunicación de las almas de no haberse inventado el lenguaje, la formación de las palabras, el análisis de las ideas. La música es como una posibilidad que no se ha realizado; la humanidad ha tomado otros caminos, el del lenguaje hablado y escrito' ${ }^{136}$.

${ }^{33}$ George Steiner, Réelles présences. Les arts du sens. Paris, NRF Essais, Gallimard, 1991, p. 219. El original difiere sensiblemente en el subtítulo, de la traducción de Michel R. de Paw: Real Presences. Is there anything in what we say?

${ }^{34}$ Gabriel Marcel, El misterio del ser. Buenos Aires, Sudamericana, 1953, p. 188.

${ }^{35}$ Rainer Maria Rilke, Die Sonette an Orpheus, Zweiter Teil, X. Una traducción aproximada dice: Pero para nosotros la exístencia todavía está encantada; en cien lugares es todavía origen. Un juego de fuerzas puras que nadie roza, si no se arrodilla y admira. Cfr. Mario $\AA$. Presas, "La magia del arte en el mundo des-encantado", Criterio, Buenos Aires, LX, N¹999-2000(1987)., pp. 690 ss.

${ }^{36}$ Proust, La prisionera, ed. cit., p. 278. 
También Rilke concluye el soneto que citamos recién con los siguientes versos:

Worte gehen noch zart am Unsäglichen aus...

Und die Musik, immer neu, aus den bebendsten Steinen, baut im unbrauchbaren Raum ihr vergöttlichtes Haus ${ }^{37}$.

${ }^{37}$ Rilke, op. cit. Una traducción aproximada diría: Las palabras se agotan suavemente en lo indecible.../ Y la música, siempre nueva, con las más trémulas piedras/ construye en el espacio inutilizable su divina morada. 